\title{
Cuidado em saúde mental: a escuta de pacientes egressos de um Hospital Dia
}

\author{
Mental health care: listening to patients discharged from a Day Hospital \\ Cuidado en salud mental: escuchando a pacientes egresos de un Hospital Día
}

\begin{abstract}
Maria Solange de Castro Ferreira', Maria Alice Ornellas Pereira"I
' Universidade Estadual Paulista Júlio de Mesquita Filho, Faculdade de Medicina, Departamento de Enfermagem.

Hospital das Clínicas. Hospital Dia de Psiquiatria. Botucatu-SP, Brasil.

"Universidade Estadual Paulista Júlio de Mesquita Filho, Faculdade de Medicina, Departamento de Enfermagem. Botucatu, SP.
\end{abstract}

Submissão: 27-10-2010 Aprovação: 05-07-2012

\section{RESUMO}

Estudo de abordagem qualitativa, tendo por objetivos compreender como os pacientes egressos de um Hospital Dia de Saúde Mental veem o serviço, conhecer se este contribuiu para mudanças em suas vidas e se estas pessoas têm continuidade ao tratamento. Utilizamos entrevistas semiestruturadas e busca documental, com nove pacientes, que concluíram tratamento no serviço, em 2008. Adotamos a Análise Temática na ordenação dos dados obtidos, analisados segundo referencial da Reabilitação Psicossocial. Ressalta-se a importância do olhar subjetivo para os diversos aspectos da existência humana, solicitando dos serviços e dos profissionais o estabelecimento de uma relação de cuidado que possibilite a reconstrução de trajetórias interrompidas pelo acometimento do transtorno, por meio de ações que considerem a integralidade e a intersetorialidade.

Descritores: Saúde Mental; Assistência; Reabilitação; Serviços de Saúde Mental.

\section{ABSTRACT}

This is a qualitative study aiming at understanding how patients discharged from a Mental Health Day Hospital view the service, at learning whether such service contributed to changes in their lives and at whether those individuals continued treatment. Semi-structured interviews and documental research were used for nine patients who had completed treatment at the service in 2008. Thematic analysis was adopted for organization of the data obtained, which were analyzed according to the Psychosocial Rehabilitation framework. It emphasizes the importance of looking for the various subjective aspects of human existence, requiring from services and professionals the establishment of a caring relationship that enables the reconstruction of trajectories interrupted by the onset of the disease, through actions that consider the integrality and intersectionality.

Key words: Mental health; Care; Rehabilitation; Mental Health Services.

\section{RESUMEN}

Este es un estudio de enfoque cualitativo que tiene por objetivos comprender cómo los pacientes egresos de un hospital de día de salud mental ven al servicio, descubrir si este ha cambiado sus vidas y si estas personas dan continuidad al tratamiento. Usamos entrevistas semiestructuradas y búsqueda documental con nueve pacientes que concluyeron el tratamiento en el servicio en 2008. Adoptamos el Análisis Temático en la ordenación de los datos obtenidos, analizados según el referencial de la rehabilitación psicosocial. Se resalta la importancia de la mirada subjetiva para los diversos aspectos de la existencia humana, solicitando de los servicios y de los profesionales el establecimiento de una relación de cuidado que posibilite la reconstrucción de trayectorias interrumpidas por el acometimiento del trastorno por medio de acciones que consideren la integralidad y la intersectorialidad.

Palabras clave: Salud Mental, Asistencia, Rehabilitación, Servicios de Salud Mental. 


\section{INTRODUÇÃO}

Considerando o evoluir histórico da atenção em Saúde Mental, vê-se que a lógica a orientar a atenção nessa área tem como eixo central a inclusão social, a partir da compreensão do transtorno mental enquanto fenômeno complexo e histórico, permeado por dimensões psicossociais, determinantes do processo saúde-doença. A Saúde Mental tem se transformado e se apresenta como campo de conhecimento complexo, solicitando práticas plurais que contemplem a diversidade da demanda.

É neste sentido que Saraceno ${ }^{(1)}$ propõe que as práticas de intervenções em Saúde Mental tenham como foco a articulação entre pacientes, serviço e contexto. Sendo assim, a Reabilitação Psicossocial é vista não como técnica de tratamento, mas como estratégia que possibilite a recuperação da capacidade do indivíduo em gerar sentido e, consequentemente, valor social, restabelecendo sua contratualidade enquanto cidadão. Portanto, a Reabilitação Psicossocial é definida como um processo que implica à possibilidade de espaços de negociação para o paciente, a família, a comunidade circundante e para os serviços que se ocupam da assistência, com o objetivo de aumentar a capacidade contratual das pessoas atendidas.

As ações governamentais se estruturam no sentido de redução progressiva dos leitos psiquiátricos, qualificação, expansão e fortalecimento da rede extra-hospitalar. É proposta a articulação de uma rede de atenção à Saúde Mental de base comunitária, com potencial de construção coletiva de soluções, como forma de garantia de resolubilidade e de promoção da autonomia e da cidadania às pessoas com transtornos mentais. Dados do Ministério da Saúde(2) apontam para uma redução gradual do número de leitos psiquiátricos no período entre 2002 a junho de 2009, passando de 51.393 para 35.426 leitos. O número de beneficiários do Programa de Volta para Casa tem aumentado, consideravelmente, passando de 879, em 2004, para um total de 3346 beneficiários até junho de 2009. Isso representa que um grande número de pacientes, com histórias de internações anteriores, passa a receber assistência neste novo sistema, emergindo a necessidade dos serviços e dos profissionais buscarem o cuidado que dê conta das exigências desta demanda que traz a "doença humanizada". Neste sentido, desinstitucionalizar é "ultrapassar fronteiras sanitárias, enfrentar o desafio da intersetorialidade e do trabalho em rede, o que implica na adoção de modelos de atenção integral de base territorial"(1).

Apesar destes avanços, a assistência em serviços substitutivos apresenta problemas a serem enfrentados. A baixa integralidade entre os serviços é frequentemente citada ${ }^{(3,4)}$. Juntamente com a dificuldade de comunicação e de informação acerca das pessoas assistidas, dificulta o acompanhamento dos subjetivos percursos marcados pela experiência do transtorno. Como consequência, ocorre um entrave no envolvimento dos serviços que oferecem assistência, havendo assim apenas o encaminhamento entre equipamentos. Desse modo, cada serviço, em meio à competência e ao nível de assistência que oferece, dá sua parcela no processo de cuidado, concede alta e o encaminhamento para continuação do tratamento, e daí para frente desconhece o itinerário de cada pessoa anteriormente assistida. Tal fato pode contribuir para o processo de objetivação do paciente, pois esse é conduzido a uma dinâmica de encaminhamentos ao longo do percurso do tratamento, sendo que nesse processo, os serviços isolados, fechados em suas rotinas, carentes de comunicação entre si, não realizam a integralidade necessária.

O processo de transformação da assistência em Saúde Mental, e a prática de trabalho neste contexto, que busca cuidar da pessoa em sofrimento psíquico, nos conduz a questionamentos: como a pessoa que vive a experiência da doença mental vivencia as mudanças decorrentes da transformação da assistência em saúde mental, e como está inserida neste novo contexto de transformação assistencial? E após o término do tratamento em um serviço substitutivo ao modelo manicomial, como vivenciam a inserção na sociedade? O serviço trouxe alguma melhoria para a vida dessas pessoas? Quais cuidados estão recebendo e em quais serviços de saúde estão? Neste trabalho procuramos investigar estas questões, que são de grande interesse para a Psiquiatria no contexto atual.

Acreditamos que a aproximação da perspectiva do sujeito que passou pelo tratamento e alta num serviço especializado possibilita a ampliação da compreensão do possível processo subjetivo de inserção social. Consideramos que nessa dinâmica, trajetórias são protagonizadas e estratégias se organizam, produzindo um saber que dificilmente pode ser captado na rotina dos serviços de saúde. Além disso, possibilita a reflexão sobre a própria prática assistencial, propiciando futuras intervenções. Desse modo, procuramos, na pesquisa aqui relatada: compreender como os pacientes egressos de um Hospital Dia de Saúde Mental veem o serviço; conhecer se o tratamento neste serviço contribuiu para mudanças na vida dos pacientes egressos; e apreender se as pessoas egressas têm continuidade ao tratamento.

\section{MÉTODO}

Utilizamos a abordagem qualitativa de pesquisa na tentativa de compreensão do significado dos fenômenos ${ }^{(5)}$. Fazem parte deste estudo nove pacientes, residentes no município de Botucatu, interior do Estado de São Paulo, que concluíram o tratamento proposto no Hospital Dia de Saúde Mental da Universidade Estadual Paulista (UNESP), no ano de 2008. Com o propósito ético de manter o anonimato, escolhemos nomes de pássaros para identificá-los.

A coleta de dados se deu no período de junho a início de agosto de 2009, após aprovação pelo Comitê de Ética e Pesquisa da Faculdade de Medicina de Botucatu, em ofício 524/08-CEP. Os dados foram coletados por meio de entrevistas semiestruturadas, norteadas por um roteiro de perguntas e busca documental, no prontuário dos sujeitos. As entrevistas foram realizadas pela pesquisadora durante as visitas domiciliares, mediante assinatura do Termo de Consentimento Livre e Esclarecido, considerando os procedimentos éticos exigidos, foram registradas em fita $\mathrm{K} 7$, garantindo a fidedignidade dos depoimentos durante a sua transcrição.

Adotamos a Análise Temática para a ordenação e análise dos dados obtidos, considerando as etapas: a) transcrição na íntegra das entrevistas; b) leitura flutuante do material 
transcrito; c) elaboração dos eixos temáticos e seus respectivos núcleos de sentido ${ }^{(6)}$. Procedemos a análise com base no referencial da Reabilitação Psicossocial|(1).

\section{RESULTADOS E DISCUSSÃO}

\section{Caracterização dos sujeitos}

Fazem parte do estudo cinco homens e quatro mulheres, com idades entre 24 a 56 anos. Apesar de jovens, apresentam, em geral, histórias longas de adoecimento psíquico. A maioria foi encaminhada ao tratamento no Hospital Dia de Saúde Mental por serviços ambulatoriais. O tempo de permanência no serviço variou de 30 a 193 dias. Considerando que o tempo médio de tratamento no serviço é de 60 dias, temos neste estudo sujeitos, que devido às demandas excepcionais, permaneceram no serviço, por um tempo superior a esta média. Após a alta do Hospital Dia, todos foram encaminhados para seguimento em outros serviços do município.

\section{$1^{\circ}$ Eixo Temático: Possibilidades No Hospital Dia}

Neste, apontamos para os sentidos da assistência vivenciada por nossos sujeitos no Hospital Dia. As categorias constituintes deste eixo temático são apresentadas a seguir:

\section{Resgate da vida anterior}

Os sujeitos falaram sobre o impacto do adoecimento em suas vidas e as consequentes repercussões nas relações familiares, sociais, e de trabalho. Nos discursos, destacam o sofrimento causado pela cisão nas trajetórias de vida, nos projetos, nos desejos, como se a vida deixasse de ter sentido, devido às causas e consequências impostas pelo próprio adoecimento psíquico.

É, trabalhava muito, eu trabalhava quase que dia e noite, e tudo que eu ia fazer, que eu faço, eu quero fazer direitinho... Então, a situação chegou num ponto que...que eu fui...que eu percebi que eu...já estava, não estava dando conta mais do recado, entendeu?. Então, quando o chefe falava para mim, ah...passava dois, três serviços, eu, eu, eu corria lá no quartinho meu e já estava marcando num papelzinho, que eu não conseguia mais guardar na cabeça, não conseguia guardar... (João de Barro)

Observamos em todos os depoimentos uma relação complementar entre o "não estar bem" e o rompimento com as rotinas da vida anterior ao adoecimento, onde a perda da capacidade de gerar sentido emerge como um dos motivos pelo qual estes sujeitos solicitam a ajuda do serviço e apresentam desejos de poderem resgatar a própria vida.

As formas através das quais o paciente pode perder sua capacidade de produzir sentido são variáveis, como: não poder mais gerar trabalho, não poder mais gerar relações afetivas com o cônjuge, não poder mais gerar relações com seus filhos, não poder mais gerar relações e trocas sociais. Neste momento, o paciente necessita de ajuda e os serviços devem estar sensibilizados para entenderem suas necessidades, suas demandas e possibilidades, a partir de exercício contínuo onde se deve pensar mais sobre as vidas reais dos pacientes e as vidas reais dos serviços ${ }^{(1)}$. Isto nos remete à reflexão de que as variáveis que determinam a evolução de uma doença mental estão parcialmente no tratamento que o sujeito recebe, mas também no tipo e na organização do próprio serviço que o atende.

Os sujeitos relatam suas percepções sobre a importância da variável serviço enquanto determinante da evolução das consequências que o adoecimento psíquico trouxe para suas vidas. Nas narrativas, o Hospital Dia é visto como um serviço que possibilitou o resgate da vida anterior ao adoecimento, um lugar onde encontraram acolhimento necessário para iniciar o processo de se refazerem novamente, sentiram-se ajudados nas demandas e, portanto, fortalecidos para a efetivação de mudanças em suas vidas.

...se eu não tivesse passado pelo Hospital Dia eu acho que eu estava numa situação bem mais difícil, né. Eu acho que eu não teria conseguido... me refazer de novo. (Beija-flor)

Para estas pessoas, o serviço contribuiu para que mudanças fossem efetivadas em suas vidas. As narrativas apontam a existência do processo de resgate da vida anterior, o restabelecer trocas afetivas e sociais, de retomarem as atividades e a autonomia, enfim, de organizarem suas próprias vidas e sentirem-se inseridos na sociedade.

Neste sentido, um elemento que apareceu com frequência nas narrativas é a restituição da condição de realizar tarefas, vistas como importantes, exercendo a autonomia e percebendo as próprias condições. Nossos sujeitos relatam a importância das tarefas de organização da casa, de atividades de lazer, de retornar aos estudos.

Agora eu consigo, pelo menos em casa, fazer alguma tarefa em casa... É, eu ajudo minha mãe limpar a casa, assim, lavar a louça.... (Andorinha)

Eu retomei a faculdade que eu faço, eu retomei alguns estágios fora da faculdade, eu retomei alguns estágios na faculdade, eu retomei aula de guitarra que eu faço, eu retomei aula de inglês... (Sabiá)

Percebe-se que cuidar do espaço em que se vive é condição primordial como garantia de responsabilidade e independência. A divisão das tarefas de casa solicita trocas e podem promover a inserção das pessoas em seu núcleo familiar enquanto participantes ativas das rotinas que compõem a vida doméstica.

Dentre as diversas atividades da vida social, estão incluídas as atividades de lazer, que se opõem à apatia e possibilitam aos indivíduos a apropriação de assuntos que podem ser compartilhados $^{(7)}$. Os sujeitos ouvidos valorizam as atividades de lazer no resgate de uma vida com sentido, sugerindo que estão retomando capacidades de desejar, de terem iniciativa, de poderem escolher o que lhes faz bem na vida.

O que eu gosto de fazer, diariamente, de manhã, de manhã cedo, hora do almoço, de tarde, fazer exercício, ficar 
andando assim lá em volta do campus, lá em volta da quadra, em volta do salão, só que eu não corro, só ando normal. (Curió)

A desabilitação é também empobrecimento da rede social, ou seja, dos lugares nos quais as trocas são possíveis, por meio de perdas qualitativas e quantitativas, inclusive no núcleo familiar. O fortalecimento das habilidades em melhorar as trocas sociais é percebido nas falas dos sujeitos, também enquanto fator positivo de mudanças em suas vidas.

"Eu nem cumprimentava as vizinhas... Agora, qualquer coisa a gente está conversando, sai, vai andar com as vizinhas, vai fazer alguma coisa..." (Cacatua)

Considerando que a doença mental traz como consequências o estigma e o isolamento social, transitar nos espaços urbanos é a possibilidade de construção de uma rede de sustentação de trocas afetivas, quando as pessoas têm a oportunidade de mostrar suas capacidades e utilidades ${ }^{(8)}$.

No entanto, as dificuldades e os desafios estão presentes nos discursos de nossos sujeitos, onde cada um relata de maneira diferenciada, encontrando recursos para lidar com as situações difíceis. Rouxinol demonstra consciência de seus sentimentos e de sua realidade, mostrando-se protagonista do processo vivido.

Eu não sei por quê... porque que eu não consigo reagir, ou porque ajo de outra forma, eu não sou uma pessoa de palavras, para agredir palavras, então me calo e aquilo ali me faz mal. Você entendeu? Fora o dia que... estou tendo ainda que fazer bastante esforço para lidar com a minha realidade, porque ... estou sozinha... (Rouxinol)

As desavenças e desarmonias familiares também são trazidas. Entendemos que estas desarmonias produzem sobrecarga emocional e, podem ser fatores determinantes na piora de sintomas ou consequentes do próprio transtorno mental. Curió tenta se afastar quando os desentendimentos estão presentes, com medo de perder o controle, elabora sua estratégia de proteção.

...por causa do meu cunhado que estava bêbado ontem, chegou bêbado, ele queria provocar, não provocou eu, provocou ela, (aponta para sua irmã) eu saí vazado, antes de provocar eu saí, ó, se não eu bato, brigo com ele, aí ele xingou eu, começou a xingar... (Curió)

As narrativas de Rouxinol e Curió nos remetem à importância de espaços de acolhimento, tolerância e convivência com aquilo que na vida subjetiva encontra-se na ordem do intratável, do sofrimento inevitável, do que não tem remédio nem nunca terá, além dos recursos terapêuticos para diminuir o sofrimento psíquico ${ }^{(9)}$, solicitando uma abordagem atenta às várias dimensões da vida humana ${ }^{(10)}$. Enfim, parece que a vida mudou, porém nem tudo ainda foi alcançado. No entanto, os desejos de mudanças e projetos futuros são identificados no discurso de Calopsita, que apresenta como principal perspectiva o retorno ao trabalho.

Então, eu não estou muito segura para trabalhar. (Silêncio) Eu penso em trabalhar, mas eu tenho medo ainda...Ah, de não conseguir trabalhar, de dar errado... (Calopsita)

O Ministério da Saúde ${ }^{(11)}$ aponta que as associações de usuários que se constituíram ao longo do processo da Reforma Psiquiátrica, têm manifestado a necessidade de projetos de trabaIhos articulados com a rede de serviços. Assim, inclusão social pelo trabalho no campo da Saúde Mental, tem encontrado na economia solidária a possibilidade de propostas concretas.

Percebe-se que as vidas das pessoas se desestruturam com o adoecimento psíquico, mas, também se vê que ações transformadoras podem possibilitar o resgate da vida anterior. Além disso, apesar da dificuldade existente na tarefa de mudar, as pessoas deste estudo não desistiram.

\section{Local de acolhimento}

As narrativas demonstram que os sujeitos veem o Hospital Dia como local continente ao sofrer psíquico, onde recebem acolhimento. A etimologia da palavra aponta que acolhimento é o ato ou efeito de acolher, recepção, atenção, consideração, refúgio, abrigo, agasalho(12). No entanto, o acolhimento na saúde, como produto da relação trabalhadores da saúde e usuários, vai além deste conceito, passando pela consideração da subjetividade, escuta das necessidades do sujeito, processo de reconhecimento e responsabilização entre serviços e usuários, além de possibilitar a construção do vínculo ${ }^{(13)}$.

Os sujeitos referem que o serviço possibilitou o entendimento de suas próprias condições. $\mathrm{O}$ aceso às informações aumenta a participação das pessoas no processo de tratamento, promove autonomia e cidadania.

E através desse Hospital Dia, do tratamento que eu recebi lá, eu pude... eu pude ter ideia do que estava acontecendo comigo. Eu comecei a entender que eu precisava mesmo do tratamento... (João de Barro)

O sucesso do tratamento encontra-se diretamente relacionado ao modo de como o paciente compreende sua doença e o que faz a partir disto ${ }^{(14)}$. Para os sujeitos, o serviço ofereceu um "bom tratamento", pois percebem que suas necessidades foram acolhidas, a consideração da subjetividade esteve presente na dinâmica do cuidado. Neste sentido, Beija-flor refere:

...eu fui tratado muito bem. Todos os exames de que foi necessário fazer na minha pessoa foi feito.. Todas as coisas que foi necessário, fizeram por mim, eu tive uma recuperação porque, teve um tratamento bom, tive um tratamento bom... (Beija-flor)

Considerando o cuidado ampliado no atendimento na área da Saúde Mental, o acolhimento do paciente, encontra-se além de estar do outro lado de uma mesa, observando seu comportamento, mas estar disposto a recebê-lo e estar com 
ele na situação, participando, tentando apreender um código desconhecido $^{(15)}$. No entanto, nas falas de Sabiá percebe-se a vivência com práticas de cuidado pautadas no modelo manicomial das instituições psiquiátricas tradicionais, onde o cuidado é fragmentado, as relações de poder disciplinar estão estabelecidas e se traduzem por meio de condutas invasivas e violentas.

Ah, eu acho muito bom, porque... eu saí de uma atmosfera ruim, que era a primeira internação no Cantídio e fui para um lugar melhor, que você não fica tão tenso,... Se existisse Hospital Dia que pudesse dormir lá mesmo eu acharia que seria uma boa ideia... do que passar por internação, a gente tem que ficar amarrado, as pessoas são agressivas, você toma remédio, muita injeção, sem motivo, aparente... (Sabiá)

Observamos que Sabiá requisita para seu tratamento, um "lugar melhor", outro tipo de cuidado, onde possa encontrar espaço de escuta e acolhimento para o sofrer. Por outro lado, Andorinha que nunca esteve internada em um Hospital Psiquiátrico e tem como referência de tratamentos anteriores os serviços ambulatoriais, sugere certa "dependência" do serviço.

...eu chego a sentir falta de lá, assim, na época eu senti medo de sair de lá, eu me senti muito segura lá dentro, assim, sabe... (Andorinha)

Assim como Rouxinol que tem a experiência de tratamento em instituição psiquiátrica.

Bom... Foi de grande ajuda, porque do tempo que eu cheguei lá, pelo que eu me recordo, eu não estava bem mesmo. Aliás, eu estava bem ruim ...É, tanto que no tempo que eu saí, eu saí bem de lá, mas... aqui fora.... é muito diferente de estar lá. (Rouxinol)

Assim, a vida que é produzida dentro dos serviços parece não se estender à vida externa ${ }^{(16)}$. Diante disso, parece necessário que o serviço esteja atento a esta forma de dependência, que sutilmente pode se instalar no processo de cuidado. Trata-se, portanto, de investir em cuidados que possibilitem ao indivíduo atuação e exercício de autonomia nos vários cenários da vida. Estar atento e cuidar desta situação é importante para o processo de enfrentamento das múltiplas demandas sociais.

O sentimento de ter sido acolhido também aparece, tendo como pano de fundo o tratamento medicamentoso, porém, destaca-se a necessidade da consideração da subjetividade, no sentido de que a medicação é considerada um instrumento facilitador de inserção social. A terapia medicamentosa realizada com critérios e cuidados é valorizada pelos sujeitos.

... é bom porque ele ajuda na diminuição dos remédios, porque você está, com uma alta...um alto...tomando bastante remédio e meio que te facilita para viver em sociedade, assim. (Sabiá)

Compreende-se que as atividades realizadas no serviço pesquisado são componentes necessários do tratamento. Os discursos mencionaram as atividades que possibilitam o exercício de rotinas da vida diária, como tempo para dormir, para se alimentar, se relacionar, ter lazer. Isso nos aponta para a reflexão da importância dos espaços informais serem significativos e utilizados pelos pacientes e, portando, de que um serviço não se constitui apenas de espaços formais, como grupos, oficinas terapêuticas, atendimentos individuais, pois o contato com o mundo é permanente e direto, no qual o paciente participa da vida e está entrelaçado por eventos cotidianos.

\section{$2^{\circ}$ Eixo Temático: assistência à Saúde Mental após alta do Hospital Dia}

Neste eixo, contemplamos as vivências de tratamento de nossos sujeitos após a alta do Hospital Dia, os equipamentos de saúde e os recursos terapêuticos utilizados na continuidade ao processo de tratamento. Neste sentido, uma única categoria, a busca de cuidado, emerge nos discursos, sendo apresentada a seguir:

\section{Busca de cuidado}

Todos os sujeitos frequentam os serviços ambulatoriais para os quais foram encaminhados após a alta do Hospital Dia. Nas narrativas, todos trazem a ideia de pertença ao serviço para o qual foram encaminhados após saída do Hospital Dia. A maioria refere que o tratamento não está centrado apenas na medicação. Assim, vemos que uma diversidade de procedimentos terapêuticos tem sido ofertada a esses pacientes, indicando a necessidade da presença de outros profissionais, além do médico, no decurso do tratamento.

...o ambulatorial da Dra Tereza., no Bloco 1. Acho que eu já tinha uma vaga lá e conforme eu saí, eu retomei, quando eu voltei, né? Aí eu tenho atividades lá e estou fazendo psicologia, também. (Sabiá)

Sim, foi o, a terapia ocupacional lá do ambulatório, no bloco 1, que eu lembre... Eu continuo tendo consultas, né. Antes de eu ir para o Hospital Dia eu já tinha consultas lá no ambulatório e continuo indo. (Calopsita)

Percebe-se a valorização da pluralidade terapêutica. Nesse sentido, emerge a abordagem terapêutica psicossocial como importante para ajudar os pacientes a trabalhar as repercussões da doença em suas vidas, na compreensão do significado de estar doente, além da conscientização sobre a necessidade de manter o tratamento farmacológico ${ }^{(17)}$. Essa questão, também, é trazida nas narrativas de João de Barro:

Só o Ambulatório com o Dr. Francisco, é terapia que eu faço, ele está, com o Dr. Francisco ele está, ele está escutando eu, orientando eu nas coisas, a lidar com a situação, né. A lidar com a situação, porque eu não achava que o meu corpo tinha limite, sabe ? (João de Barro)

A consideração das dimensões biológicas, psicológicas e sociais envolvidas no adoecimento, possibilita um olhar 
menos fragmentado e reducionista ao paciente e seu sofrimento, apontando para a importância de ações coerentes com as necessidades dos pacientes e inclusão destes como participantes ativos no processo de tratamento ${ }^{(18)}$.

No entanto, observamos a centralização dos encaminhamentos para o ambulatório de Saúde Mental. Constatamos que os equipamentos das redes básicas de saúde, como as Unidades Básicas, o Centro de Saúde Escola e as Unidades que contemplam a Estratégia de Saúde da Família não são utilizados por nossos sujeitos na continuidade ao tratamento em Saúde Mental. A atenção à Saúde Mental parece estar em um isolamento especializado de competência exclusiva da psiquiatria. Esse descompasso compromete o entrelaçamento de ações, e, consequentemente, a efetividade dos serviços, já que os equipamentos funcionando isoladamente, apresentam dificuldades na otimização de ações. Nessa perspectiva, a qualidade da assistência e o olhar voltado para o cuidado ampliado podem estar prejudicados.

A integralidade e a intersetorialidade aparecem nas falas de Cacatua, como componentes importantes de ajuda para a continuidade do tratamento.

Daí é todo mês a médica pede para ir, para não faltar. Tratar lá, eles tratam super bem a gente. A Dra Catarina é um amor de pessoa. Então, todo mês tem aquele, aquele, aquele..., todo mês tem que estar ali, certinho, então é um cuidado especial com gente de verdade, não é uma coisa do médico, sabe, já tá bom, pode sair, pode ir embora, não é. É uma coisa, que continuou, vai andando e enquanto não ficar bom ela diz que não para. (Cacatua)

Considerando o contexto dos novos paradigmas da atenção em Saúde Mental, onde o enfoque do cuidado se desloca do diagnóstico para o indivíduo e seus problemas, a questão da integralidade necessita ser abordada, determinando um olhar integral da situação ${ }^{(3)}$. Para tanto, a intersetoriaridade e a diversificação devem ser consideradas componentes indissociáveis da integralidade ${ }^{(3)}$. Vê-se que no caso de Cacatua, um olhar integral à sua situação foi de fundamental importância para a adesão ao tratamento. Os registros demonstram que Cacatua, sem crítica sobre seu estado, queixava-se apenas de cefaleia nas consultas médicas realizadas na unidade básica de saúde e era medicada para tal. Enquanto isso mergulhava em sintomas psicóticos que lhe impediam de viver, permanecendo nessa situação, sem tratamento adequado, por cinco anos.

A questão do trabalho é trazida por Curió, que tentou participar de uma oficina terapêutica, antes mesmo de ser encaminhado ao Hospital Dia, mas encontrou dificuldades e não aderiu ao seguimento:

Porque eu fui, já fui na Oficina Girassol, lá, fiquei uns tempos lá, ganhava dinheirinho, um pouquinho. Mas, é que eu enjoei, comecei a enjoar, enjoei. Porque lá é longe de casa... (Curió)

Para Curió, conforme relatado no prontuário, o adoecimento, os vários abandonos ao tratamento e as muitas internações em Hospitais Psiquiátricos limitaram suas habilidades laborais, desde muito cedo. Observamos que esta questão, por muitos anos, não foi cuidada nos tratamentos a que ele foi submetido. Isso nos sugere que a relação de Curió com a questão do trabalho ficou adormecida por muito tempo.

Mais uma vez, destaca-se a importância da ampliação da Economia Solidária e da Empresa Social, enquanto promotoras de condições reais de ingresso ou retorno das pessoas que se encontram em condições de desvantagem social no mundo do trabalho ${ }^{(19)}$

Vê-se, também, que, no relato de Curió, está presente a importância dada ao território. Para ele, estar inserido em um serviço pertencente ao seu território facilita seu tratamento. Isso nos aponta para a importância da inclusão da concepção de território nas estratégias de Saúde Mental, visando à expansão e consolidação de uma rede de atenção extra-hospitalar como garantia de atendimento das demandas territoriais específicas.

\section{CONSIDERAÇÕES FINAIS}

A busca pelo cumprimento dos objetivos propostos no presente estudo possibilitou uma aproximação da perspectiva do sujeito que recebeu cuidados no Hospital Dia, de vivências subjetivas, do sofrimento causado pelo adoecimento psíquico, enquanto fator marcante e desagregador da vida dessas pessoas, solicitando uma assistência que considere as necessidades complexas dos indivíduos e o acolhimento do sofrimento.

A investigação aponta para a importância dos serviços de Saúde Mental irem além do instituído, se apropriarem da responsabilidade do cuidado ampliado, aliada ao comprometimento dos profissionais. Esses fatores emergem como determinantes da evolução das consequências do adoecimento psíquico e ocupam papel relevante no processo de mudança de vida.

Para os sujeitos, o serviço ofereceu o acolhimento, mostrando-se continente ao sofrer psíquico, contribuiu para o processo de retomada da autonomia e inserção social, possibilitando a efetivação de mudanças na vida.

Os resultados, também, apontam que os sujeitos dão continuidade ao tratamento em Saúde Mental após a alta do Hospital Dia e valorizam a pluralidade terapêutica oferecida. Por outro lado, evidencia-se a necessidade de ações que considerem a integralidade e a intersetorialidade, uma vez que foi observada restrita comunicação entre serviços que assistem nessa área e a centralização dos atendimentos em um serviço especializado em Saúde Mental, sugerindo a fragilidade de uma rede de atenção em Saúde Mental no município.

Considerando que a doença mental ainda é um fenômeno psicossocial que requer melhor compreensão, é certo que a pessoa que vivencia o sofrimento psíquico necessita ser cuidada, valorizada e estimulada a reencontrar uma vida com sentido. Desse modo, função importante dos serviços é contribuir para que haja transformações significativas nas vidas das pessoas, apesar do sofrimento inerente ao transtorno mental. 


\section{REFERÊNCIAS}

1. Saraceno B. Libertando Identidades: da Reabilitação Psicossocial à Cidadania Possível. Rio de Janeiro: Te Cora; 1999.

2. Ministério da Saúde (Brasil) Saúde Mental em Dados-6, ano IV, $n^{\circ} 6$. Informativo eletrônico [periódico na internet]. 2009 jun [acesso em 09 set 2009] Disponível em: $<$ http://www.ccs.saude.gov.br/saude_mental/pdf/smDados/2008_SMD_06.pdf>.

3. Alves DS. Integralidade nas Políticas de Saúde Mental. In: Pinheiro R, e Matos RA, organizadores. Os Sentidos da Integralidade na Atenção e no Cuidado à Saúde. Rio de Janeiro: UERJ, IMS, ABRASCO; 2001.

4. Pinto TR. Encontros e Desencontros: a Estratégia de Saúde da Família em sua relação com a rede de serviços e dispositivos substitutivos em Saúde Mental. Botucatu. Dissertação [Mestrado em Saúde Coletiva] - Faculdade de Medicina de Botucatu, Universidade Estadual Paulista, 2007.

5. Turato ER. Métodos qualitativos e quantitativos na área da saúde: definições, diferenças e seus objetivos de pesquisa. Rev Saúde Pública 2005;39(3):507-14.

6. Bardin L Análise de Conteúdo. 3. ed. Lisboa: Edições 70; 2004.

7. Salles MM, Barros S. O caminho do doente mental entre a internação e a convivência social. Imaginário USP 2006; 12(13):397-418.

8. Dalmolin BM, Vasconcellos MP. Etnografia de sujeitos em sofrimento psíquico. Saúde Pública 2008;42(1):49-54.

9. Bezerra júnior B. O Cuidado nos CAPS: os novos desafios. [artigo na internet] 2000 [acesso em 01 nov 2009] Disponível em <http://www.saude.rio.rj.gov.br/saude/ pubsms/media/cuidado_nos_caps.pdf $>$.

10. Pandroni RFS, Padilha MICS. Loucura e complexidade na clínica do cotidiano. Esc Anna Nery Rev Enferm 2006;10(4):623-34.
11. Ministério da Saúde. Secretaria de Atenção à Saúde/ DAPE. Saúde Mental no SUS: acesso ao tratamento e mudança do modelo de atenção. Relatório de Gestão 20032006. Ministério da Saúde; 2007.

12. Ferreira A B H. Novo dicionário Aurélio da Língua Portuguesa. 3.ed. Rio de Janeiro: Positivo; 2006.

13. Bueno WS, Merhy EE. Os equívocos da NOB 96: uma proposta em sintonia com os projetos neoliberalizantes? [artigo na internet]. [acesso em 01 nov 2009] Disponível em: < http://www.datasus.gov.br/cns/ temas/NOB96/ NOB96crit.htm $>$ (acessado em novembro de 2009).

14. Spadini LS, Souza MCBM. A doença mental sob o olhar de pacientes e familiares. Rev Esc Enferm USP 2006;40(1):123-7.

15. Goldberg GJ. Reabilitação como processo - o Centro de Atenção Psicossocial - CAPS. In: Pitta A, organizadora. Reabilitação Psicossocial no Brasil. 2. ed. São Paulo: Hucitec; 2001. p.33-45.

16. Amorim AK, Dimenstein M. Desinstitucionalização em Saúde Mental e práticas de cuidado no contexto do serviço residencial terapêutico. Ciênc Saúde Coletiva 2009;14(1):195-204.

17. Bettarello SV, Greco F, Filho LMAS, Silva MCF. Fundamento e Prática em Hospital-Dia e Reabilitação Psicossocial. São Paulo: Atheneu; 2008.

18. Jorge MSB, Ramirez ARA, Lopes CHAF, Queiroz MVO, Bastos VB. Reabilitação Psicossocial: visão da equipe de saúde mental. Rev Bras Enferm 2006;59(6):734-39.

19. Lussi IAO. Trabalho, reabilitação psicossocial e rede social: concepções e relações elaboradas por usuários de serviços de saúde mental envolvidos em projetos de inserção laboral. Ribeirão Preto. Tese [Doutorado em Ciências]- Universidade de São Paulo; 2009. 